\title{
Problem of the Human Capital Quality Reducing in Conditions of Educational Unification
}

\section{Elena G. Popkova}

Volgograd State Technical University, Volgograd, Russia, ap. 33, 11a Dvinskaya St. Volgograd, Russia, 400087

Email:210471@mail.ru

\section{Oxana S. Chechina}

Samara State Technical University, Samara, Russia

\section{Sergei A. Abramov}

Volgograd Economical-Technical College, Volgograd, Russia

\section{Doi:10.5901/mjss.2015.v6n3s6p95}

\section{Abstract}

\begin{abstract}
Educational unification is contradictory process. One hand, it opens up new opportunities and promotes international cooperation and collaboration, promotion of international labor migration. On the other hand, it has a direct impact on the quality of human capital. The results of the quality of human capital are implemented through labor. Only high-quality human capital in conjunction with innovative factors of production can ensure the growth of labor quality, product quality and productivity, and ultimately improve the competitiveness of the economy. Therefore, the quality of human capital determines the opportunities for economic development that determines the relevance of the study. The article raises the problem of the possibility of standardizing such a specific system of education, which is based on the unique cultural heritage of each country. There is no doubt that destroys the relationship of culture and education is easy, but to build a new system of education based on international principles that are alien to the society, it is impossible. It is necessary to preserve the cultural heritage and traditions in the process of unification of education, as Les, the new educational system does not take root, which will certainly lead to a reduction in the quality of human capital.
\end{abstract}

Keywords: educational unification, human capital quality, informatization, modernization, socio-economic development.

\section{Introduction}

Human capital is the most important factor in modern socio-economic development, improving the quality of people's lives. It can provide innovative economic development, increase productivity only in circumstances where a person has a high quality professional, qualifications and intellectual ability, the ability to fully implement them in their work.

In a globalizing world economy is enhanced labor migration, which makes it inevitable unification of education, a manifestation of which is the establishment of uniform educational standards and principles in the various countries of the world. The undeniable advantage of the unification of education is to expand opportunities for international cooperation in the field of education, as well as facilitating international labor migration. However, a serious problem of unification of education is to reduce the quality of human capital.

\section{Materials and Methods}

The object of study is problem of the human capital quality reducing in conditions of educational unification.

Lately, more and more in-depth study of human capital developed countries, as evidenced by some changes in the methodology used by OECD countries in the preparation of hedgehog-fit reviews in the field of education.

Thus, the effectiveness of the educational system in OECD countries is estimated based on several criteria (Zapata, 2013):

- level of adult education;

- number of students graduating from higher vocational schools;

- impact of the level of parental education on children's access to higher education; 
- impact of education on participation in the labor market;

- $\quad$ wages and education;

- impact of education on economic growth, labor costs and labor income;

- social outcomes of education.

Over the last decade (2004-2014 years), GDP growth in OECD countries (over 50\%) is due to the high level of human capital - labor income of people with higher education. As for the prospects of development of human capital, the forecasts for the 27 countries of the European Union as well as Norway and Switzerland show that in the period from 2010 to 2020 for employment will be offered to approximately 80 millions of jobs of which nearly 7 million are new (OECD, 2014).

Most of the net increase in employment will be determined by the professions that require high qualifications. For ten years, the proportion of such jobs will increase from 29 to $35 \%$. In this profession average will continue to be about half of all jobs, and the proportion of unskilled jobs will be reduced from 21 to $15 \%$ due to structural changes and increased competition. In order to adapt to the new conditions of workers need to expand access and improve the relevance and quality of training prior to employment, to provide them with more opportunities for training in conjunction with measures of active policy in the labor market (Levin, 2012).

A significant part of the staff will have to increase the number of their skills and improve their quality. Increasingly important, in addition to purely technical skills, competencies and acquire related social interaction skills, including the ability to effectively make contact and communicate with other people, to reach a mutual agreement, to assist and take the lead.

Masters also do research and teach in universities. Meanwhile, Russia today is faced with the paradox that a twotier system of education leads to an almost complete cessation of training qualified personnel, because qualification Bachelor designed primarily for support functions (Popkova \& Tinyakova, 2013a).

In Japan, the proportion of graduate students is $9 \%$, in China - almost $15 \%$ in the UK - 22\% (probably due to student mobility). Let us analyze some of the results of the processes of modernization of education in 2014 (Table. 1).

Table 1. Comparison of some indicators of the effectiveness of the education system in Russia and OECD countries, 2014

\begin{tabular}{|lccc|}
\hline Indicator & $\begin{array}{c}\text { Russian } \\
\text { Federation }\end{array}$ & $\begin{array}{c}\text { OECD countries in } \\
\text { general }\end{array}$ & $\begin{array}{c}\text { Place of the Russian } \\
\text { Federation in the rating }\end{array}$ \\
\hline Involvement in higher education: & $29 \%$ & $17 \%$ & 6 of 33 countries, \\
Professional Education (Tertiary-type B) & $66 \%$ & $62 \%$ & 12 of 36 countries \\
\hline university programs (Tertiary-type A) & $5,5 \%$ & $6,2 \%$ & 28 of 37 countries \\
\hline Public expenditure on education,\% of GDP & $35,4 \%$ & $30 \%$ & 9 of 31 countries \\
\hline Share of private investment in higher education & 7749 & 13728 & 31 of 37 countries \\
\hline Training costs per student, dollars &
\end{tabular}

Source: OECD, 2014. Synergies for Better Learning: An International Perspective on Evaluation and Assessment (2014) http://dx.doi.org/10.1787/9789264190658-en (Accessed on February 4, 2015)

OECD countries by investing in education, receive economic and social benefits (net income by an average of more than US \$ 100000 from the income tax, which is 4 times the investment in education to a man and a factor of 2.5 - per woman). Due to the global trend to reduce the rate of population growth and the share of the working age population aged 25-59 years, economic growth will depend primarily on the skills and productivity. Therefore it is necessary to rely on bachelors, raising and equating their status to the established in other participating countries of the Bologna process (Lyche, 2010).

This study used the reproductive approach to the study of the quality of human capital, based on the principle of consistency and the principle of "process-outcome" allows us to draw a conclusion. As part of this approach by the quality of human capital should be understood stable set of properties of its structural elements forming the professional qualifications and intellectual abilities, continuously enriched in the process of accumulation of knowledge, experience, skills, and ensure the growth of the quality of work (Altbach, 2014). 


\section{Results}

Comparative analysis of the characteristics and trends of the educational systems of different countries reveals two basic models, significantly different approaches to the implementation of the mechanisms of state regulation in the field of education.

To refer to these models, we introduce the conventional names: liberal and quasi-administrative.

Liberal model is more typical for countries with economies that are committed to democratic values, with a long tradition of respect for university autonomy and academic freedom (Kiley \& Mullins, 2014).

Administrative model type is typical for countries that had recently planned economy with strict government regulation and command-administrative management. These include Russia and other countries of the former Soviet Union. The economies of most of these countries today is characterized as a transition or even the market, although the mechanisms of management in the field of education retain all the features of management models that have emerged in the administrative-command management style planned economy. All the exposed more clearly the ineffectiveness of these models in the new economic environment and allows us to characterize them as administrative.

Briefly describe the main differences liberal and administrative models. In this case, specify that the type of national education systems of individual countries, as a rule, is mixed. Therefore, in any country, this system can be characterized only as a predominantly liberal or primarily administrative (Nyquist, 2012).

The main asset of the liberal model is a true academic freedom and university autonomy. University implements established in each educational programs that meet only the most general requirements of state regulation that can be attributed to these programs to university type. In the liberal model of universities may also decide to upgrade the existing and open any new educational program without getting the permission or the educational authorities, or anywhere else. The quality of educational programs in the liberal model guarantees the independence of state institutions accreditation of these programs. Universities, taking care to raise the status of their educational programs, accredit them respected independent accreditation organizations: professional associations, national and international accreditation agencies, etc. (Kuijpers \& Scheerens, 2013).

The classification system of educational programs in the liberal model is part of the national education statistics developed by national authorities and statistics for the convenience of international comparisons is constructed as comparable to the International Standard Classification of Education (ISCED-97). National system determines the classification rules of educational programs and subsystem includes vertical and horizontal classification. Vertical subsystem classifies educational programs on levels of education, horizontal - on areas of professional activity: for advanced groups (analogues of consolidated groups in the Russian classification) and educational fields (similar to training areas in the Russian version). Educational fields can be further detailed by subfields (Russian counterparts options clarify the profile of the educational program is specialty of the education and specialization) (Popkova \& Tinyakova, 2013b).

A characteristic feature of the national classification systems of administrative model educational programs is the fact that the classification system is combined with the lists of educational programs. Therefore, any changes in the skill mix of training related to the introduction of new educational programs in any educational institution of vocational education require changes to the relevant Russian classifiers. Consequently, the system of conducting all-Russian classifiers in the field of education, continuous updating them and bringing the current version to the users is cumbersome and inefficient (Popkova et. al., 2013).

In a global world of information, increasing the social role of information and knowledge of education is undergoing significant transformation, becoming a key quality of labor. Increasingly adopted the view, according to which the old system of presenting information, the model of education, working as a factory, should disappear.

Modern education is not just a process of "knowledge transfer" from the teacher / instructor to pupil / student, as it was in the traditional education system. The dual purpose of education is to transmit to future generations the values of culture and teach them to live in a rapidly changing world. Achieving this goal is possible only if the formation of the student autonomy (Blondal et. al., 2011).

Modernization of education is not only the transformation of its content, but also the form. Today, there is a significant interest in the problems of education quality management, models, organizational forms and methods of educational process on the part of those who are directly or indirectly related to the education system, especially the educational community.

It is impossible not to draw attention to the fact that the modern processes of standardization of education ambiguously perceived not only educational community, but also the public at large. One of the issues under discussion the question of what is the direction of standardization of education: whether it is the necessary basis for new 
improvements of both the educational process and its results, or entail inertia, as a barrier to further improvement?

Understanding of standardization as a way to streamline organized integrity and ensure its stability allows us to conclude that the standardization and standards are essential to the formation and functioning of the education system as an organized whole. Standardization of education is an activity aimed at the establishment of rules, regulations and requirements of the educational process and its results in order to achieve the optimal order and stability of the system of education. Educational standard as a normative document defines the content, scope and requirements for the training of graduates and, according to experts, is the basis of an objective assessment of the level of education.

General trends in the spread of global standards in the modern world are manifested in the harmonization of standards of training. Thus, in accordance with the requirements for standardization of quality management systems of education, adopted by the international community, the following main principles of standardization of education (Le Métais, 2013):

- State licensing of educational institutions;

- voluntary application of standards (self-assessment);

- the interests of consumers of educational services;

- applying international standards (Bologna agreement);

- uniformity in the application of national standards;

- introduction of scientific and technological progress;

- improving the competitiveness of educational institutions;

- unity of assessing the quality of education in different educational institutions;

- protection of students from the external environment;

- modular training system based on the selection of disciplines.

New requirements for the organization of educational process and management have led to the need for the development and implementation of new standards of education, aimed at solving the strategic objectives to improve the content and technology education. At the state level shall be programs aimed at adapting the international standardization system for the Russian education.

Thus, it becomes evident that in order to avoid the standardization and uniformity in the educational process in the integration of the educational system of Russia in the international educational space, on the one hand, and the deconstruction of educational space - on the other hand, need educational standardization. It is achieved through adherence to existing socio-cultural, educational standards - traditions, spread in a given society, aimed at the reproduction of socio-cultural experience and the introduction of international standards as a natural result of contemporary processes of globalization and informatization of the world. Due to poly-standardization provided variability of education, its compliance with international, state and regional requirements.

\section{Discussion}

The situation today with the higher education system is inconsistent. Sociologists studying the problem of education, clearly indicate a serious crisis of the institution and the reduction of real education, linking it in the first place, with a general dissatisfaction with its quality. Here are the claims of both employers and students themselves, who want to get more specific skill that can immediately be converted into higher wages. At the same time, sociologists fix a stable demand for education among students. This phenomenon can be called "the totality of education". People tend to get a diploma of higher education in the hope of obtaining admission to the world of high-paying jobs.

The education system should be reconstructed under the requests of "clients" - employers and society by implementing a learning process strictly coordinated practical skills that graduates would use in the future, but for some reason, the inside it has not happened or did not happen to the fullest.

Society, representing the set of elements of the social system must be based on a certain basis for what, in fact, it is structured. Such a basis for the origin of all forms of social institutions, social relations and personal experience is a sociocultural matrix, and its formation depends on various conditions - geographical, historical, cultural and religious. If such a sociocultural matrix exists in the context of society, therefore, it exists in the context of its institutions. As higher education is a social institution, it can be assumed that it is based on the socio-cultural matrix of higher education (Baram-Tsabari \& Lewenstein, 2013).

The socio-cultural matrix of higher education is a set of meanings and values invested in education society and its individual agents, at four levels of social space: the material, ideal, socially and culturally. The socio-cultural matrix of higher education is a key factor in the reproduction of human capital. That it is the prism through which education looks 
society and its individual agents. It determines the preference of people in the choice of a profession, the trajectory of the educational program, forms of organization of educational process, educational institution, etc.

In any society, there is an objective socio-cultural process. In this process, laid two contradictory trends: on the preservation of culture and its change. In this encounter is born sociocultural contradiction, there is some discrepancy between the existing relations, social practices, and the existing culture, its core (Bernstein, 2011).

Sociocultural contradiction leads to a change of culture and its social space, but not to its destruction - provided, of course, if this contradiction is not included in absolute conflict, in which case it would be a socio-cultural disaster, when the system is degraded. The socio-cultural matrix of higher education is a structure where the socio-cultural process flows, and its elements - a subject field, where changes occur.

Viewed from this perspective, it becomes obvious: the globalization of economy and culture lead to dysfunction of the individual elements of social and cultural matrices of higher education, enshrined in national states. As an example, it suffices to recall the Bologna process: it does not live up to expectations in full, bumping into the pitfalls of social, cultural and financial differences. Each of the countries participating in the process for many centuries formed its own unique history of socio-cultural matrix of higher education. It is this matrix, especially not in a short period, European higher education system internationalizes. And today, remains an open question, would not a change in socio-cultural matrix of individual nation-states to their destruction.

The process of birth is accompanied by a new form of the withering away or partial displacement of the same. A single nation-state in the sociocultural process generates its own mechanism to solve problems and emerging needs, peculiar to this culture, and attempt to replace one another mechanism may lead not to the solution of current social or cultural problems, and to its aggravation. Reproduction of human capital once again comes to the fore.

\section{Conclusion}

The University is a tool for transformation and a source of preservation of traditions it contributes to the development and simultaneously inhibits it. This internal contradiction is due to the socio-cultural matrix of higher education. In the context of economic relations, such competition should spur to improve the educational product, but led to a rise in the cost of its value, putting a large social group in the position of outsiders.

With the implementation of the knowledge economy on a global scale social inequalities inherent in the elite education, which moves the modern system of higher education, the widespread modernization and computerization will lead to the fact that persons serving high-end technologies to decrease significantly. The greater part of grown-up population can go to the service sector, where the need for workers is minimal, and the level of remuneration is sufficient in order to live in a society of mass consumption.

In this case, the universities, for centuries remained the flagship of higher education and the social institution of education, waiting for the inevitable death, as for the reproduction of human capital will be used by other mechanisms, other institutions. The socio-cultural matrix of higher education in the context of the reproduction of human capital provides, first of all, the implementation of socio-cultural needs of the society.

The University is a special social institution that stands above the social groups and individuals, and as such it has proved to be the best way. In this sense, it would be useful to study the socio-cultural matrix of higher education inherent in the different types of universities, in particular, to determine in which direction to pursue a policy of reform in order to improve the quality of higher education, not its destruction.

\section{References}

Altbach, P. G. (2014). Higher education crosses borders. Change, 36, 18-25.

Baram-Tsabari, A., \& Lewenstein, B. V. (2013). An instrument for assessing scientists' written skills in public communication of science. Science Communication, 35(1), 56-85.

Bernstein, B. L. (2011). Managing barriers and building supports in science and engineering doctoral programs: Conceptual underpinnings for a new online training program for women. Journal of Women and Minorities in Science and Engineering, 17(1), 29-50.

Blondal, K., J. Jónasson and A.-C. Tannhäuser. (2011). Dropout in a Small Society: Is the Icelandic Case Somehow Different? School Dropout and Completion: International Comparative Studies in Theory and Policy, Springer Science+Buisness Media B.V.

Kiley, M., \& Mullins, G. (2014). Examining the examiners: How inexperienced examiners approach the assessment of research theses. International Journal of Educational Research, 41, 121-135.

Kuijpers, M. A., \& Scheerens, J. (2013). Career competencies for the modern career. Journal of Career Development, 32, 303-319

Le Métais, J. (2013). International Developments in Upper Secondary Education: Context, Provision and Issues, Research Report No. 2, 
INCA Thematic Study No. 8, National Council for Curriculum and Assessment, Dublin.

Levin, B. (2012). More High School Graduates: How Schools can Save Students from Dropping Out, Corwin: A Sage Company, United States of America.

Lyche, C. (2010). Taking on the Completion Challenge: A Literature Review on Policies to Prevent Dropout and Early School Leaving. OECD Education Working Papers, No. 53, OECD Publishing. http://dx.doi.org/10.1787/5km4m2t59cmr-en (Accessed on February 4, 2015).

Nyquist, J. (2012). The PhD: A tapestry of change for the 21st century. Change: The Magazine of Higher Learning, 34(6). Pp. 12-20

OECD. (2014). Synergies for Better Learning: An International Perspective on Evaluation and Assessment (2014) http://dx.doi.org/10. 1787/9789264190658-en (Accessed on February 4, 2015).

Popkova, E.G. and Tinyakova V.I. (2013). New Quality of Economic Growth at the Present Stage of Development of the World Economy. World Applied Sciences Journal, 5: Pp. 617-622.

Popkova, E.G. and Tinyakova V.I. (2013). Drivers and Contradictions of Formation of New Quality of Economic Growth. Middle-East Journal of Scientific Research, 11: Pp. 1635-1640.

Popkova, E.G., Morkovina S.S., Patsyuk E.V., Panyavina E.A. and Popov E.V. (2013). Marketing Strategy of Overcoming of Lag in Development of Economic Systems. World Applied Sciences Journal, 5: Pp. 591-595.

Zapata, J. (2013). Upper Secondary Practices and Challenges in OECD Countries and a Literature Review. OECD Working Papers, OECD Publishing. 